that of the star projector, which makes the stars appear in the darkened room as points of light in a twilight sky. As the projector rotates on its axis once in 20 minutes, the stars swing slowly across the face of the dome in this time, and students are able to gain true impressions of the form, location, and interrelations of the constellations much more clearly than they can from star charts. The apparatus supplies the nearest approach to the actual study of the heavens from outdoor instruction. The latter is not always a satisfactory method when large groups. of students have to be considered, and in addition, weather conditions and the season of the year are disturbing factors. The star projector is a most important adjunct to-day in pilot training when speed is so essential.

\section{Effects of Altitude}

According to the Journal of the American Medical Association of October 24 a law was recently passed by the Senate of Argentina for the creation of a committee to supervise studies on the effects of altitude. The committee, which will consist of medical men, chemists, physicists and biologists, will form a branch of the Ministry of Internal Affairs. The field covered by the committee will be (1) biological problems in relation to the most adaptable human biotypes ; (2) working capacity, feeding, housing and climatological, hydrological, geological, zoological, botanical and physiochemical factors in relation to the life of normal men in various altitudes ; (3) pathology of altitudes, studies of diseases which may be improved by hypsotherapy, and the establishment of sanatoria and hospitals and proper altitudes for the cure of certain diseases; (4) creation of portable laboratories and establishment of experimental hypsological centres; and (5) studies of the animals and plants of different regions, the constitution of the soil and meteorological phenomena.

\section{Folk-Lore of Children's Diseases}

Aт a meeting of the Folk-Lore Society on January 20 , Dr. J. D. Rolleston read a paper on the folk-lore of children's diseases. The field is extensive, since it covers the popular conceptions of the acute exanthemata and other infectious diseases, especially whooping cough and diphtheria, venereal infections, cardiac, respiratory, alimentary disorders and isolated diseases, especially erfuresis, infantile convulsions, rickets, hernia and the supposed effects of the 'evil eye'. As regards causation, belief in the doctrine of maternal impressions is still far from extinct, although there is no scientific foundation for such a view. The recognition of astrology by orthodox medical practitioners survived until the eighteenth century, as was shown by Mead's work. The visitation of the 'evil eye' also accounted in popular estimation for many diseases, especially in countries bordering on the Mediterranean. Although a vast number of more or less irrational and inexplicable beliefs were connected with the newborn period, comparatively few of them were of medical interest. Dentition, like menstruation and pregnancy, is a normal process, and was much less frequently the cause of disease than was popularly supposed, especially by mothers who were liable to regard any of their infants' ailments as due to this cause. In like manner, tongue-tie, though often alleged by a mother to account for her child's inability to take the breast, was usually non-existent.
The belief in the superstition that venereal disease could be cured by transfer to healthy young virgins of either sex was still prevalent, and was one of the chief causes of acquired syphilis or gonorrhoea in children. Although in other departments of medical folk-lore, especially dermatology, ophthalmology and otology, prophylaxis has received much less attention from the folk than curative treatment, in the case of children's diseases, much more importance seems to have been given to prevention than in other branches of folk-medicine. Examples of the kind were the use of salt for guarding the newborn against evil demons and evil influences, the use of amulets and the administration of coral in the mother's milk.

\section{Infant Mortality in the United States}

Is a recent article on infant mortality in rural and urban areas in the United States (Public Health Rep., 57, 1494 ; 1942), Herbert J. Sommers, of the United States Public Health Service, states that the infant mortality-rate in the registration areas of the United States has been reduced by more than a half. From 1915 until 1929 the urban rate, though higher than the rural in every year, decreased more rapidly than the rural, so that in 1929 , for the first time on record, the rate was lower in urban than in rural areas, and since then the urban rate has remained lower than the rural. The rates were generally higher in the south than in other regions and rural rates were generally highest in the Middle West. The reduction in infant mortality which has taken place in cities is to be attributed to increasing emphasis being laid on the principles of sanitation, the establishment of 'well-baby' clinics, the increasing use of hospitals for delivery, the compulsory pasteurization of milk and the application of modern medical knowledge.

\section{Physical Education}

Is a lecture delivered before the Anglo-Swedish Society and published in the December issue of the Anglo-Swedish Review on the development of physical education in Great Britain and the Dominions, Miss P. Spafford, organizing secretary of the Ling Physical Education Association, said that organized physical education in Great Britain and the Dominions originated in the elementary schools, while the educational, medical and recreative gymnastics were based on Per Henrik Ling's principles. In newly built schools throughout the country conditions for physical education are excellent. Many have their own swimming bath as well as a field for games and a gymnasium. The physical education scheme in schools in Canada, South Africa, Australia and New Zealand is largely that carried out in British schools. The War has inevitably caused a certain set-back in physical education owing mainly to a shortage of gymnastics and game schooling as well as a lack of gymnastics equipment. The most popular physical activity in all the countries of the British Commonwealth is swimming. Physical training in the Services is based on the Swedish and Danish systems and is closely linked up with recent research in physiology and psychology. "Until recently there has been little or no organized physical training in the universities, although there has always been sport of various forms. There is a real need for further instructional cooperation, and further research is essential, especially into the physiological basis of exercises. 